ARTICLE

Received 21 Mar 2014 | Accepted 15 Oct 2014 | Published 25 Nov 2014

DOI: $10.1038 /$ ncomms 6572

OPEN

\title{
Inclusion flotation-driven channel segregation in solidifying steels
}

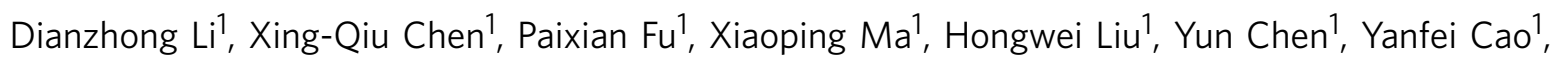
Yikun Luan ${ }^{1} \&$ Yiyi Li ${ }^{1}$

Channel segregation, which is featured by the strip-like shape with compositional variation in cast materials due to density contrast-induced flow during solidification, frequently causes the severe destruction of homogeneity and some fatal damage. An investigation of its mechanism sheds light on the understanding and control of the channel segregation formation in solidifying metals, such as steels. Until now, it still remains controversial what composes the density contrasts and, to what extent, how it affects channel segregation. Here we discover a new force of inclusion flotation that drives the occurrence of channel segregation. It originates from oxide-based inclusions $\left(\mathrm{Al}_{2} \mathrm{O}_{3} / \mathrm{MnS}\right)$ and their sufficient volume fraction-driven flotation becomes stronger than the traditionally recognized interdendritic thermosolutal buoyancy, inducing the destabilization of the mushy zone and dominating the formation of channels. This study uncovers the mystery of oxygen in steels, extends the classical macro-segregation theory and highlights a significant technological breakthrough to control macrosegregation.

\footnotetext{
${ }^{1}$ Shenyang National Laboratory for Materials Science, Institute of Metal Research, Chinese Academy of Sciences, Shenyang 110016, China. Correspondence and requests for materials should be addressed to D.L. (email: dzli@imr.ac.cn).
} 
$\mathrm{D}$ efects in materials often cause various failures in the service process. A typical defect, which is referred to as macrosegregation ${ }^{1-6}$, frequently occurs during solidification. It reflects a phenomenon of chemical compositional variation, which appears in the range from several millimetres to centimetres or even up to metres in castings and ingots. Although this defect was initially described in bronze gun barrels nearly half a millennium $\mathrm{ago}^{7}$, the theory of macrosegregation ${ }^{4,6}$ was pioneered by Flemings and co-workers about half a century ago. Until then, macrosegregation was considered to be a result of gravity-driven flow due to density contrast during solidification. Currently, macrosegregation is induced by three known forces: the buoyancy force of the natural thermosolutal convection ${ }^{8}$, the solid movement force of the grain settling or flotation, and the shrinkage force of the volume contraction during solidification. Macrosegregation is generally classified as various types ${ }^{4-6,9}$ based on shape and position. The most typical and severe one is the channel segregation (CS, also referred to as 'A segregates $4,5,9$ ', 'freckle ${ }^{6,10}$, 'chimneys ${ }^{11}$ ' or 'compositional stratification ${ }^{3}$ ), which have long been a subject of investigation in the fields of metallurgy, geophysics ${ }^{12,13}$ and geology ${ }^{14}$. CS in steels was substantially attributed to the interdendritic thermosolutal buoyancy force due to the density contrast between solute-enriched melt and bulk liquid ${ }^{15,16}$, according to the classical macrosegregation theory 4,6 . In this context, the corresponding modelling $5,10,17-21$ was developed to simulate the formation of macrosegregation.

Given the fact that classical macrosegregation theories have been extensively accepted and well-documented in the textbooks, there seems no reason to suspect their incompleteness. However, it does exist ${ }^{6}$. Based on these theories, CS will unavoidably appear in large steel ingots as the inter-dendritic thermosolutal convection will be very intense due to tall and sufficient sections. For instance, CS definitely occurs in a 100-ton ingot due to an extensive period of solidification (over $25 \mathrm{~h}$ ) and a slow average cooling rate (approximately $<5^{\circ} \mathrm{Ch}^{-1}$; see Supplementary Figs 1,2 and Supplementary Note 1). Unexpectedly, the examinations of our synthesized 100-ton steel ingots with a total oxygen (T.O) concentration of $\sim 1.0 \times 10^{-3}$ wt.\% revealed that the CS was not observed in the fully dissected cross-section (as discussed below). This fact does not correspond to the expected occurrence of CS from the classical theories, which motivates the exploration of its mechanism in solidifying steels. Via systematic investigations of various dissected ingots $(0.5,5,5.8,14,16,20,69,100,234$, 535 and 650 (ref. 22) tons; see Supplementary Figs 3-9, Supplementary Table 1, and Supplementary Notes 2 and 3), we have discovered the fourth force of light oxide-based inclusion flotation to drive the formation of macrosegregation. This force is capable of destabilizing the mushy zone by altering the flow fields of their surrounding melts and dominates CS formation. It demonstrates that CS can be significantly reduced or even completely eliminated in subsequent solidified ingots through the upstream low-oxygen purifying metallurgy, which is intrinsically different from traditional methods. From the viewpoint of engineering applications, this study may rapidly yield practical benefits to the annual global manufacture of over 50 million tons of ingots, heavy plates and castings ${ }^{23}$.

\section{Results}

Experimental characterizations of inclusions and CS. To address this mechanism, we have designed five Experiments (I-V), as compiled in Table 1. Substantial differences are observed in the fully dissected, etched longitudinal sections of ingots I and II (Figs 1a and 2a). Experiment I exhibits typical CS with some narrow, vertical and centre-inclined axial-symmetrical strip-like chains (Fig. 1a), whereas the CS disappears in Experiment II (Fig. 2a). Their differences are observed in the employed deoxidation techniques and the pouring methods, which result in a highly distinct oxygen concentration. In the former I, the T.O is $5.6 \times 10^{-3} \mathrm{wt} . \%$ with the $\mathrm{AD}$ and air pouring treatments, whereas the VCD and vacuum pouring treatments yield T.O $=1.0 \times 10^{-3}$ wt.\% in the latter II (Table 1). The analysis reveals that the inclusions enriched in the $\mathrm{CS}$ region of the Experiment I (Fig. 1b) are primarily composed of $\mathrm{Al}_{2} \mathrm{O}_{3}, \mathrm{MnS}$ and minor amounts of bubble-like cavities (see Supplementary Figs 10-16 and Supplementary Note 4). A special feature has been regularly observed in the CS region, in which the majority of $\mathrm{MnS}$ (Fig. 1d,e) tends to combine with $\mathrm{Al}_{2} \mathrm{O}_{3}$ (Fig. 1b) to form the $\mathrm{Al}_{2} \mathrm{O}_{3} / \mathrm{MnS}$ oxide-based inclusions (OIs); they almost have a diameter in the range of $\sim 5 \sim 50 \mu \mathrm{m}$. The typical morphologies include the MnS-like impurity precipitates surrounding the centred $\mathrm{Al}_{2} \mathrm{O}_{3}$ (Fig. 1c). Some main elements are also promoted to segregate, which corresponds to the occurrence of OIs (see Supplementary Table 2). Compared with Experiment I, the amount and size of the OIs, which are dependent on the oxygen concentration, have been significantly reduced in Experiment II (Fig. 2a). Thus, the contrasting experiments between I and II imply that the oxygen concentration seems to be the crucial factor for CS formation.

To elaborate the effects of oxygen in Experiment III, we have retained T.O $=1.5 \times 10^{-3}$ wt.\% with the VCD technique but have adjusted the $S$ concentration to a higher level of $1.3 \times 10^{-2}$

Table 1 | Operating conditions and results of eight designed experiments (We have summarised a total of 18 dissected ingots, which are weighted from 0.5 to 650 tons in Supplementary Table 1).

\begin{tabular}{|c|c|c|c|c|c|c|c|c|}
\hline \multirow[t]{2}{*}{ Expt. } & \multicolumn{3}{|c|}{ Condition } & \multicolumn{5}{|c|}{ Result } \\
\hline & Mass (ton) & Pouring Method & Deoxidation & T.O (10 ${ }^{-3}$ wt.\%) & C (wt.\%) & S (wt.\%) & P (wt.\%) & CS \\
\hline I & 0.5 & Air & $A D$ & 5.6 & 0.47 & 0.016 & 0.020 & Yes \\
\hline II & 0.5 & Vac. & VCD & 1.0 & 0.47 & 0.005 & 0.005 & No \\
\hline IV & 0.5 & Vac. & VCD & 2.0 & 0.07 & 0.005 & 0.007 & Yes* \\
\hline $\mathbf{v}$ & 0.5 & Air & VCD & 0.7 & 0.45 & 0.008 & 0.009 & No \\
\hline VI & 100 & Vac. & VCD & 1.0 & 0.22 & 0.005 & 0.006 & No \\
\hline
\end{tabular}

Here, ${ }^{\star}$ denotes slight CS and ${ }^{* *}$ denotes very slight CS

The $A D$ and VCD techniques denote the aluminium deoxidation and the vacuum carbon deoxidation, respectively. T.O, C, S and P represent the average total oxygen concentration, carbon concentration, sulphur concentration and phosphorus concentration, respectively. 

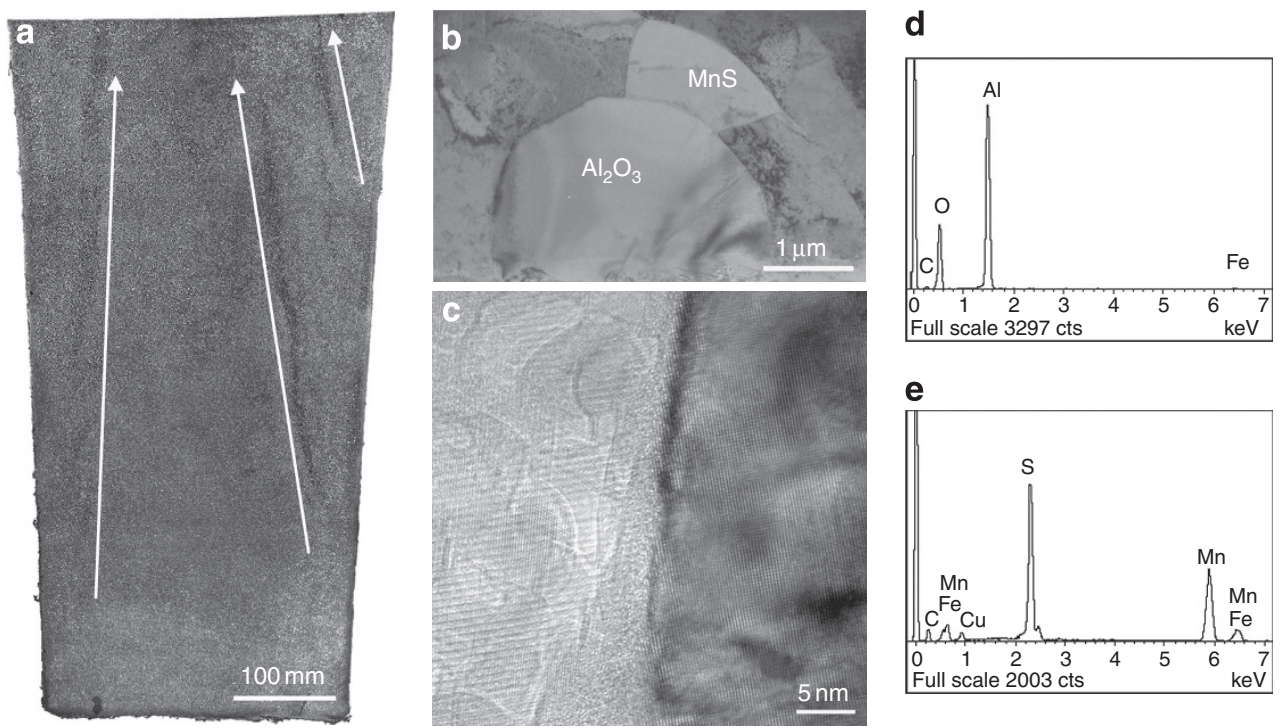

Figure 1 | Occurrences of CS and Ols. (a) Experiment I: The sectioned surface of the Al-deoxidation 0.5-ton ingot has been cut along the axle plane. The surface has been etched by dilute nitric acid to display the microstructures and CS as indicated by arrows. (b) The TEM image shows that the MnS combines with the $\mathrm{Al}_{2} \mathrm{O}_{3}$ to form Ols in the region of the CS. (c) High-resolution TEM image to analyse the interface between $\mathrm{MnS}$ and $\mathrm{Al}_{2} \mathrm{O}_{3}$. (d,e) The EDS results for $\mathrm{Al}_{2} \mathrm{O}_{3}$ and $\mathrm{MnS}$ in $\mathbf{b}$.

a

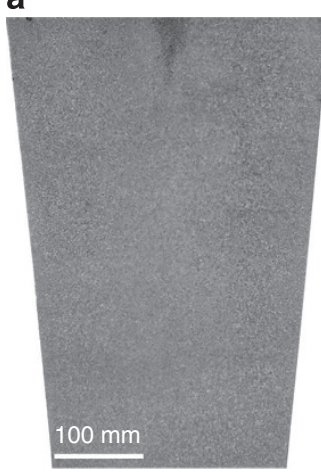

b

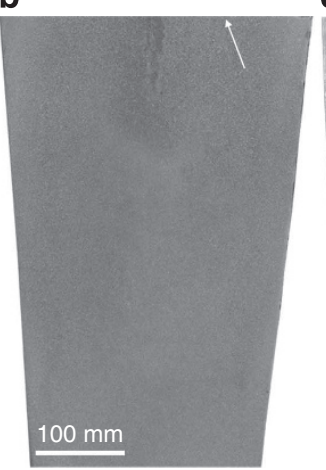

c

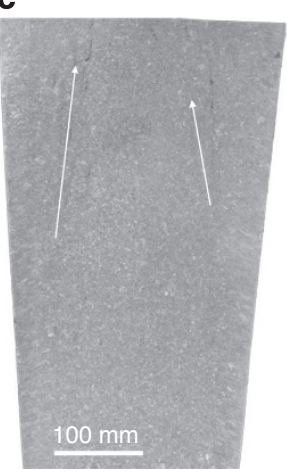

d

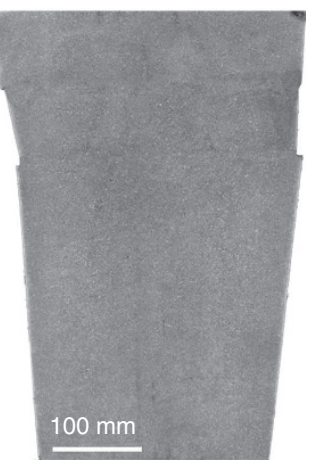

Figure 2 | Existence and elimination of CS. The sectioned surfaces of four 0.5-ton ingots have been treated by the VCD technique and cut along the axle plane. (a) Experiment II: CS disappears with T.O $=1.0 \times 10^{-3}$ wt.\%. (b) Experiment III: CS has been significantly reduced with T.O $=1.5 \times 10^{-3}$ wt. $\%$. (c) Experiment IV: CS occurred with T.O $=2.0 \times 10^{-3} \mathrm{wt} . \%$ in the presence of a small amount of OI. (d) Experiment V: CS has disappeared in this ingot poured in the air by argon protection as long as the oxygen concentration has been limited to a low level T.O $=0.7 \times 10^{-3}$ wt. $\%$. The arrows denote the presence of CS.

wt.\% (Table 1). Similar to Experiment II, the amount of CS has been significantly reduced (Fig. 2b), despite the existence of a relatively large amount of dispersed $\mathrm{MnS}$ in Experiment III. Using the VCD technique, the CS appears as long as a higher concentration of oxygen exists, as elucidated by our Experiment IV (Fig. 2c) of a 0.5-ton vacuum poured ingot with a T.O of $2.0 \times 10^{-3}$ wt.\%. In contrast, the CS disappears in Experiment $\mathbf{V}$ (Fig. 2d) with a lower oxygen concentration of the T.O $=0.7$ $\times 10^{-3}$ wt.\% (Table 1) by the VCD technique poured in the air by the argon protection. We extended our experiments to a series of significantly heavier ingots (that is, 5, 5.8, 14, 16, 20 and 69 tons; see Supplementary Table 1 and Supplementary Methods). In this similar situation the CS becomes very slight or disappeared only if the oxygen concentration is controlled to a low level (typically, the T.O is $\sim 1.0 \times 10^{-3}$ wt.\%), regardless of which methods (AD or VCD, air or vacuum pouring) have been employed. These results clarify that the oxygen concentration has a primary effect on CS formation.
Multiscale modelling. As the dissolved oxygen concentration is $<1.0 \times 10^{-3}$ wt. $\%$ in steel melt treated by the $\mathrm{AD}$ technique, the $\mathrm{Al}_{2} \mathrm{O}_{3}$ in the $\mathrm{CS}$ would most likely not form via the chemical reaction between aluminium and oxygen during the solidification. In the refining process, the high melting point oxide of $\mathrm{Al}_{2} \mathrm{O}_{3}$ $\left(>2,000{ }^{\circ} \mathrm{C}\right)$ is unavoidably formed in traditionally metallurgical practices. If the $\mathrm{AD}$ technique is adopted in the final stage of the refining process, a certain amount of $\mathrm{Al}_{2} \mathrm{O}_{3}$ particles with diameters $<10 \mu \mathrm{m}$ should not float rapidly, according to the Stokes law, which dictates that the floating velocity is proportional to the square of the particle's diameters. Thus, these small particles will be buried into melts. Owing to the weak wettability of $\mathrm{Al}_{2} \mathrm{O}_{3}$ particles during the solidification process, they would not only be inclined to agglomerate together but would also adsorb the surrounding S, Mn or other ions to form a larger OI (Fig. 1b) and become more buoyant. While the inter-dendritic microsegregation certainly enhances these adsorptions, their behaviours would also be chemically evidenced by our first-principles calculations. 
Owing to the strong electronic hybridizations among $\mathrm{S}$ and its nearest neighbours $\mathrm{O}$ and $\mathrm{Al}$ on the surface, $\alpha-\mathrm{Al}_{2} \mathrm{O}_{3}$ favourably traps the free $\mathrm{S}$ ion and binds with $\mathrm{Mn}$ ion to initially nucleate the MnS-like cluster (Fig. 3a). As shown in Fig. 3b, the calculations also indicate that, as the number of $S$ ions trapped by one absorbed $\mathrm{Mn}$ ion on the surface increases, the adsorption energies (Fig. 3b) and the binding energies (Fig. 3c) of the Mn- $n$ S-like clusters weaken. Similar behaviours have been observed for the adsorption of additional $\mathrm{Mn}$ ions. The calculations highlight the following trend: as nucleated $\mathrm{Mn}+n \mathrm{~S}$-like clusters coarsen to the crystalline phase on the surface, their interface binding energies with the substrate of $\mathrm{Al}_{2} \mathrm{O}_{3}$ weaken, which eventually causes their separation (see Supplementary Note 5 and Supplementary Figs 17-20). This situation is experimentally identified in the CS strips (see Supplementary Fig. 10).

According to the classical theoretical framework, the flow instability in the inter-dendritic region that is caused by the melt convection, which is faster than the movement of the solidification front, is the essential underlying mechanism of CS formation ${ }^{4}$. Our mesoscale phase-field simulations coupled with the fluid flow dynamics reveal that the inter-dendritic solute convection in $\mathrm{Fe}-\mathrm{C}(0.36 \mathrm{wt} . \%)$ alloy is weak (typically $\sim 10 \mu \mathrm{m} \mathrm{s}^{-1}$ ) and slower than the isotherm rate; therefore, no
CS is expected to occur (see Supplementary Note 6 and Supplementary Figs 21-23). Once a large population of properly sized OIs is introduced, our simulations reveal the occurrence of CS, as shown in Fig. 3d,e. This finding is attributed to the sufficient volume fraction of the OI population that induces the flow instabilities in the mushy zone, as illustrated by the simulations of $\mathrm{CS}$ in $\mathrm{Fe}-\mathrm{C}(0.36 \mathrm{wt} . \%)$ steels using the multiphase flow approach (see Supplementary Note 7). Figure 3d visualizes the simulated carbon distribution in the cavity within a unidirectional solidification, which demonstrates CS evolution. The simulated flow fields, the wavy isolines of solid fraction and the distribution of alumina in the cavity are demonstrated in Fig. 3e. The alumina concentrated along the CS strips is distinct.

Note that our simulations revealed that the appropriate size and population of OIs are two essential factors that affect CS formation. Within our current modelling, the most appropriate diameter of OIs, which is the first factor, has been determined to fall within the range of $5 \sim 30 \mu \mathrm{m}$. These OIs can efficiently enhance the local liquid flow, and alter its direction, which causes flow instability and the destabilization of the mushy zone. However, the size of OIs cannot be too small (that is, $<5 \mu \mathrm{m}$ ) or large (that is, $>30 \mu \mathrm{m}$ ). The results demonstrated that the OIs with diameters $<5 \mu \mathrm{m}$ float weakly and slowly to drift with the a

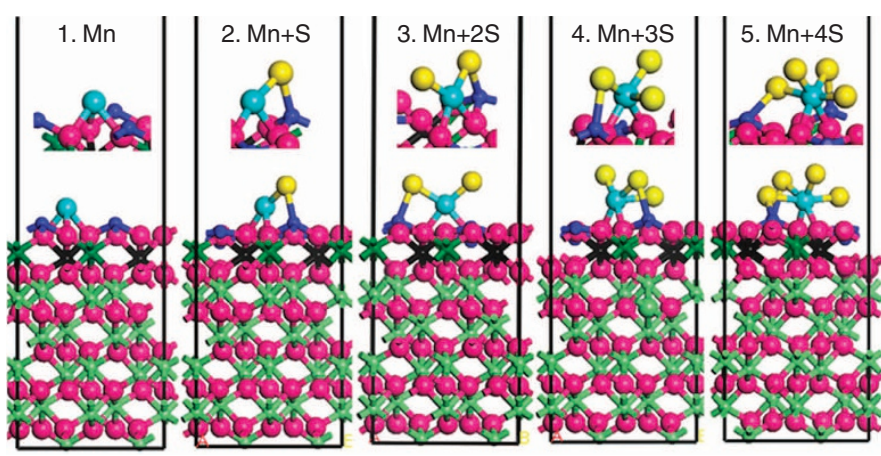

b

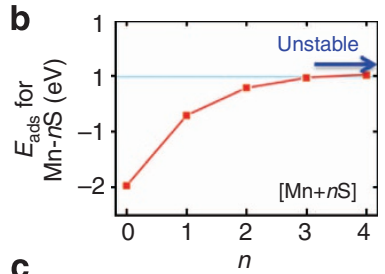

C

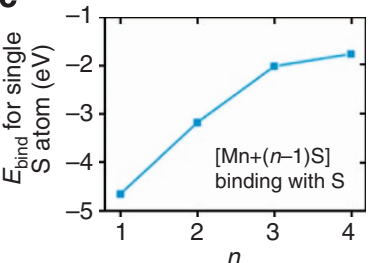

d

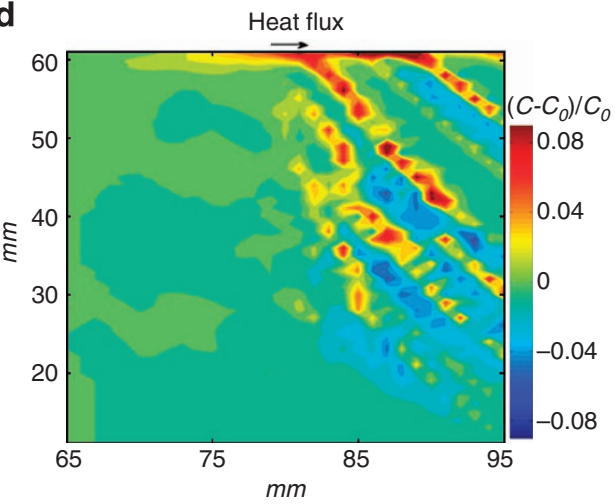

e

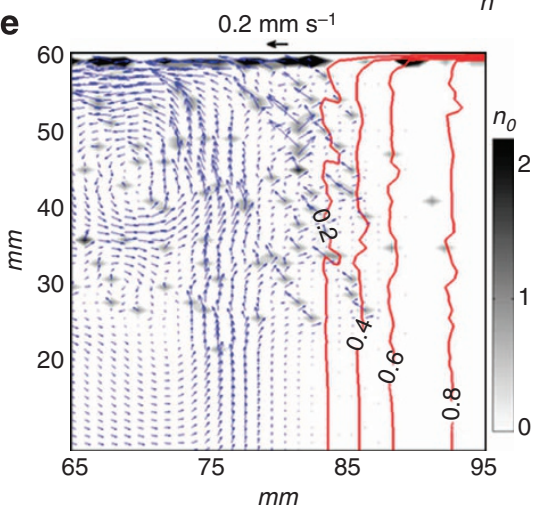

Figure 3 | Nucleation of Ols and their inclusion-driven flotation. (a) The first principles calculations simulated the nucleating process $\mathrm{Mn}+n \mathrm{n}$ clusters by trapping $\mathrm{S}$ and $\mathrm{Mn}$ ions on the $\mathrm{Al}_{2} \mathrm{O}_{3}$ (0001) surface. The upper panels denote the local geometric structural details for the $\mathrm{Mn}$ or $\mathrm{Mn}+n \mathrm{~S}$ adsorptions. Blue and yellow balls denote the $\mathrm{Mn}$ ions and $\mathrm{S}$ ions, respectively. Depending on the $\mathrm{S}$ introduction to the $\mathrm{Mn}+\mathrm{nS}$ atom complex, the bonding length between $\mathrm{Mn}$ and the nearest neighbouring $\mathrm{O} 1$ atoms has been slightly reduced from $n=0$ to $n=2$ and is subsequently increased for the cases of $n=3$ and 4 . This feature corresponds to the stable adsorption for $n=0,1$ and 2 due to the enhanced attraction between the trapped Mn atoms and the trapped $\mathrm{O} 1$ atoms on the surface. The increasing distance for the $n=3$ and $n=4$ cases reveals the weakening of the adsorption. (b) The adsorption energies of the $\mathrm{Mn}+n \mathrm{~S}$ atom complex on the surface as a function of the trapped $\mathrm{S}$ ions. (c) The binding energies have been obtained from the $\mathrm{Mn}+n \mathrm{~S}$ complex with respect to the extra-S atom and the already formed $\mathrm{Mn}+(n-1) \mathrm{S}$ complex on the $\mathrm{Al}_{2} \mathrm{O}_{3}(0001)$ surface. (d) The simulated CS of Fe-0.36 wt.\% C steel coupled with the flotation of the initial 500 alumina particles (Ols) with a diameter of $15 \mu \mathrm{m}$ is unidirectionally solidified in a cavity $\left(100 \times 60 \mathrm{~mm}^{2}\right)$. (e) Detailed information of the liquid flow patterns in the mushy zone and the distribution of solid particles, which demonstrates that the floating particles perturb the flow field by accelerating the local flow velocity and altering its direction. The isolines of the solid fraction are also superimposed in the figure. The legend on the right shows the number of particles $n_{0}$. 
current of the thermosolutal convection or to be captured by solid, whereas the OIs with large diameters $>30 \mu \mathrm{m}$ rapidly float into the top bulk melt and their influences on the solidifying melt easily vanish. We found that this theoretical diameter range $(5 \sim 30 \mu \mathrm{m}$; see Supplementary Note 7 and Supplementary Fig. 24) of OIs to induce CS formation corresponds with our experimentally observed scale (predominantly $5 \sim 50 \mu \mathrm{m}$ ) (see Supplementary Note 4). The discrepancies can be primarily attributed to the limitations of our modelling as we neglected the coagulation, growth and blocking of dendritic networks for OI. For the second factor, the modelling simulation also revealed that, as the population of the initial OIs with a diameter of $15 \mu \mathrm{m}$ increases, the CS strips increase and become more significant (see Supplementary Fig. 25). At the adjacent onset site of the CS formation, the local volume fraction of OIs is estimated to be a minimum of $0.01 \%$ according to our simulations. Using the $3 \mathrm{D}$ X-ray tomography technique in Experiment I (see Supplementary Note 4 and Supplementary Figs 26,27), the volume fraction of OIs at the adjacent onset site of the CS formation is measured to be $\sim 0.09 \%$, which is within the same order of magnitude as our estimated data. Within the body of the CS region, the maximum measured volume fraction is $0.35 \%$, which is one order magnitude larger than the adjacent onset site. This fact reflects the coagulation and growth of OIs during CS formation. These results convince us that the large volume fraction of the OI population with appropriate sizes and quantities induces the destabilization of the mushy zone and dominates CS formation.

\section{Discussion}

The OI flotation-driven CS occurrence has been neglected in long-term scientific and engineering practices. Thus, we defined this neglected flotation as a new driving force. During solidification, the fine OIs agglomerate and grow in multiple locations at a certain distance from the side wall of the ingot. These sufficient OIs in the mushy zones, which are featured by low solid fraction, will float up spontaneously, and, during their flotation, some OIs that are obstructed by dendrite arms will preferentially move incline-upwards due to the thermal field. Mechanically, the floating of the large population of OIs will effectively perturb the flow fields in the mushy zone and alter the local flow patterns, which destabilizes the mushy zone (see the wavy isolines of the solid fraction in Fig. 3e) and triggers the origin of the CS. As the destabilized mushy zone advances, the flotation of OIs not only drags the surrounding solute-rich melts to flow together but also causes the enrichment of adjacent OIs, low melting point impurities (that is, some sulphides) and bubbles. These retain the successive interactions with their surrounding melts and generate the macroscale CS occurrence, as illustrated in Fig. 4. Owing to the suck or adsorbed solute elements and sulphides (that is, MnS) around the OIs, they would lower the local melting point and re-melt or erode the dendritic trunks and branches, enrich and float up together, which promote the formation of CS. Despite the difficulty of dynamically observing this real-time process of CS formation, we trust that this mechanism is highly suggestive. In addition to this inclusion flotation, note that the interfacial tension-driven flow may serve a specific role in coagulating the impurity particles ${ }^{24}$ and reshaping the clusters of inclusions in the strip-like chains via the capillary force in streams.

It is worth noting that the previous established theories by experimental and numerical studies reveal that the thermosolutal convection is the essential factor that is responsible for the formation of CS in some superalloys ${ }^{25,26}$, aluminium alloys ${ }^{1}$, model alloys (Ga-25 wt.\%In (ref. 11), Sn-5 wt.\%Pb (ref. 27),

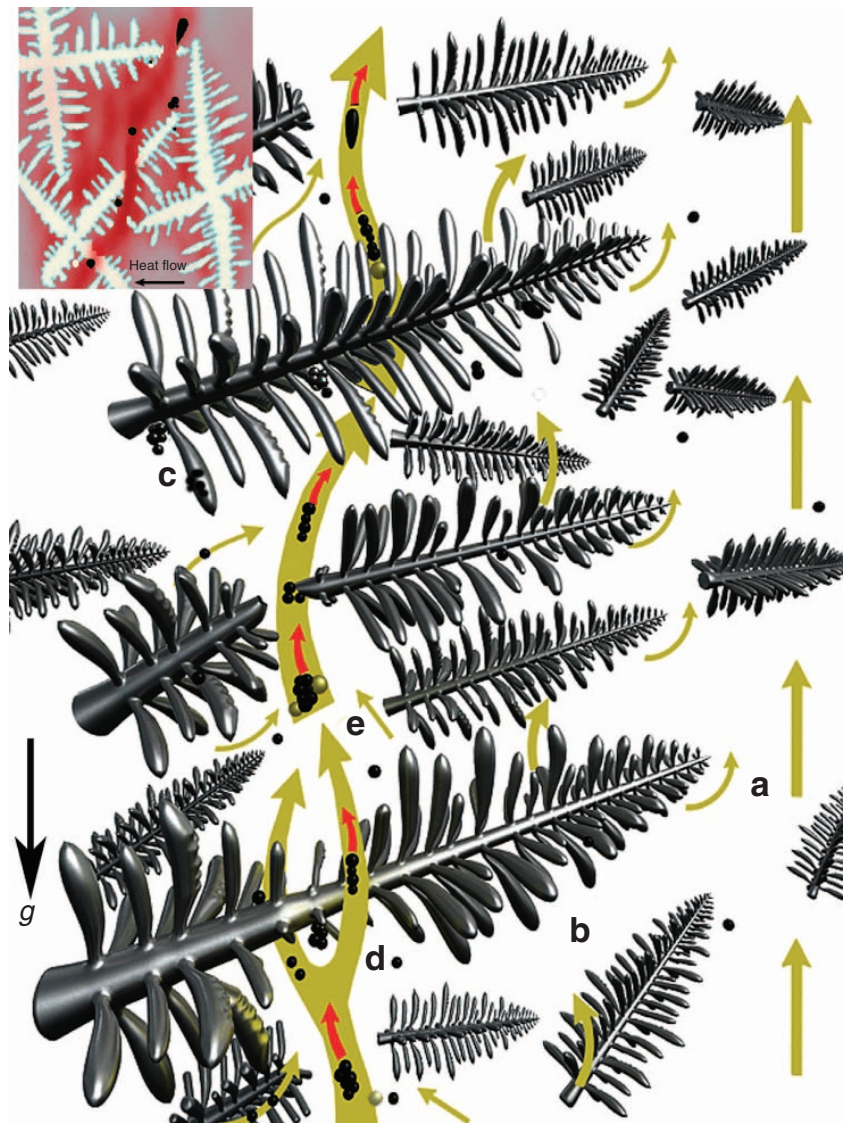

Figure 4 | Schematic of inclusion flotation among the inter-dendritic regions. The schematic reveals the three-dimensional dendritic growth around the sidewall of the ingot. The inset shows the two-dimensional projection of the inter-dendritic regions. Five flotation modes have been highly suggested: (a) solute-enriched melts run along the primary dendrite into the bulk melt and float up in front of the dendrite tips; (b) soluteenriched melts vertically float across the dendrite trunks and branches; (c) the floating Ols are blocked by the dendrites; (d) together with the floating of accumulated Ols and minor amounts of bubbles, further re-melt, erode the dendrites to form an extra non-thermosolutal flow, and the flow channels are formed by the inclusion flotation and the introduction of its correlated solute-enriched melts; (e) the interfacial tension-driven flow coagulates and reshapes the clusters of Ols to strip-like chains. Solid spheres and yellow balls denote inclusion particles and gas bubbles, respectively. $g$ denotes the gravity.

Sn-20 wt.\%Bi (ref. 28), and so on.) and even a few special steels (that is, high $\mathrm{Si}$ steels ${ }^{29}$ ). In these alloys, the high density contrast between the inter-dendritic melt and the bulk liquid is sufficient to drive intensive melt convection and produce CS (see Supplementary Fig. 28, Supplementary Note 7 and Supplementary Table 3). In the extensively applied steels, the concentration of the main element-carbon-is at least one order of magnitude less (typically, $[\mathrm{C}]<0.77 \mathrm{wt} . \%$ ) than these alloys; thus, the density contrasts in the melt cannot drive this strong convection. It is therefore difficult for the weak melt convection to induce the CS formation, but the OIs flotation does.

As a new mechanism for CS formation, it has to be examined in engineering practice. Three 100-ton industrial ingots (VI, VII and VIII in Table 1) with a diameter of $2.4 \mathrm{~m}$ and a height of $3.6 \mathrm{~m}$ have been produced by vacuum pouring, two ingots (VI and VIII) have been produced by the VCD technique and one ingot VII has been produced by the $\mathrm{AD}$ technique. As expected, 
a

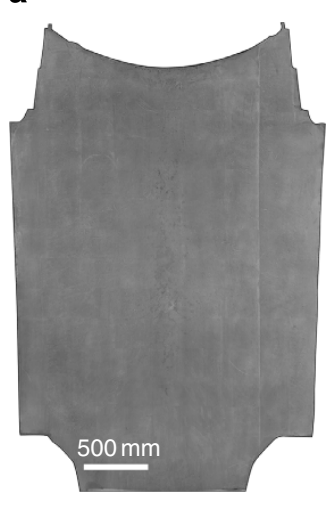

b

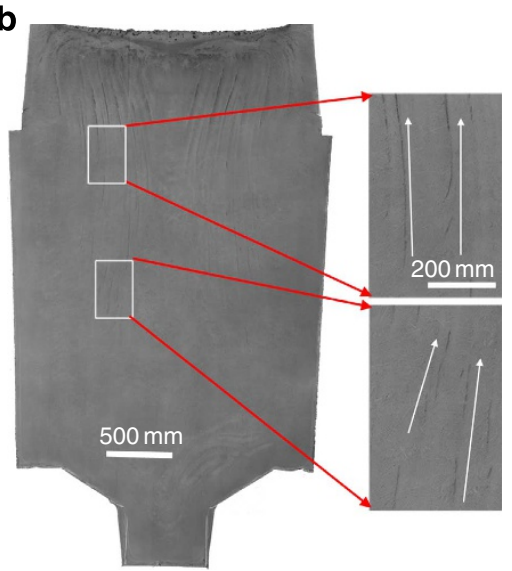

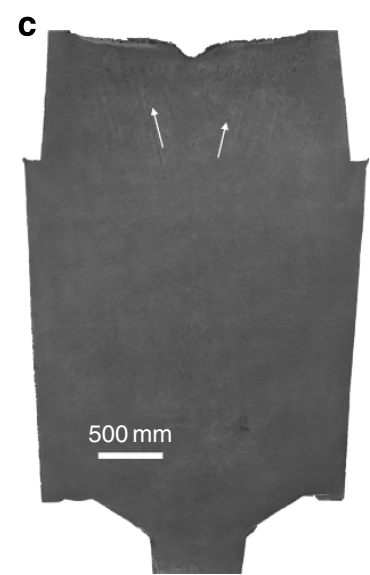

Figure 5 | The fully sectioned and etched surfaces of three 100-ton ingots. These ingots consist of 30Cr2Ni4MoV steels with a diameter of $2.4 \mathrm{~m}$ and a height of $3.6 \mathrm{~m}$. The arrows denote the CS. (a) Experiment VI: in the VCD technique, no CS is visualized. (b) Experiment VII: in the AD technique, the local slim CSs are indicated by arrows. (c) Experiment VIII: in the VCD technique, no CS has been observed in the ingot body, with the exception of two short slim CSs, as denoted by two arrows in the top feeder.

almost no CS is observed in the fully dissected cross-section of Experiment VI (see, Fig. 5a), which corresponds to our current theoretical analysis due to the lower oxygen concentration with T.O $=1.0 \times 10^{-3}$ wt.\%. In Experiment VII, the pre-heated and insulation feeder techniques have been adopted to reduce the centre-line porosity defects, while a small amount of $\mathrm{Al}$ is fed into the refining ladle to analyse the effect of oxygen concentration and OIs on the CS. The results reveal the presence of a few slim CSs enriched with $\mathrm{Al}_{2} \mathrm{O}_{3}$ (Fig. 5b and see Supplementary Movie 1) in the coarsened dendritic grain zones due to a slightly higher T.O $=1.5 \times 10^{-3} \mathrm{wt} . \%$. This experiment validates the conclusion: oxygen is a source for initializing the CS in solidifying steels. By combining the techniques of Experiments VI and VII, avoiding the use of the $\mathrm{AD}$ technique and lowering the oxygen concentration to T.O $=1.2 \times 10^{-3}$ wt.\%, the third 100-ton ingot (Experiment VIII) has been successfully produced. This ingot is perfect, as we expected. No any CS is detected in the body of the ingot, with the exception of two slim CSs in the top feeder (Fig. 5c and see Supplementary Movie 2). As listed in Supplementary Table 1, the mechanism has been re-confirmed in the large ingots (234 and 535 tons) by our collaboration partners of the heavy metal industries (see Supplementary Notes 2 and 3); it also matches the previously reported results for a 650-ton ingot ${ }^{22}$.

In traditional metallurgy, the CS in steels is primarily controlled in the solidification process via rapid cooling, mechanical vibration and electromagnetic stirring ${ }^{5,6}$, and so on. Increasing the cooling rate not only accelerates the freezing of liquid melt but also limits the flotation of OIs. The mechanical vibration and electromagnetic stirring externally alter the morphology of microstructures, which naturally affects the flow behaviour of the OIs. To some extent, these technologies may exert certain effects on the prohibition of CS but they exhibit intrinsic limitations to the applications in heavy steel ingots due to the thick thermal diffusion boundary layer and heavy bulk melts. Our current findings challenge the traditional approach to preventing CS formation from solidification control to upstream metallurgy control. Namely, via the low-oxygen purifying technology for maintaining a low level of T.O (typically, T.O $<1.0 \times 10^{-3}$ wt.\%) and jointly limiting the other impurity elements (that is, S and P), the CS can be controlled in engineering practice. This purifying technology represents a significant breakthrough to pin the CS occurrence, which is operable and efficient for the industrial manufacture of steel ingots, slabs and castings. Conceptually, this approach comprises an innovative method in which the role of inclusion flotation highlights a new horizon and demonstrates a substantial difference from the traditionally recognized buoyancy force of natural convection. This investigation on the inclusion flotation reveals the underlying effect of oxygen on CS formation in steels and the importance of the control of oxygen concentrations in the steel industry, besides the already recognized manipulations of the elements $\mathrm{C}, \mathrm{Si}, \mathrm{Mn}, \mathrm{S}$ and P.

\section{Methods}

Experiments of ingots. Five experimental steel ingots $(500 \mathrm{~kg}$ carbon steels (Experiments I, II, III, and V) and an alloying steel (Experiment IV) have been synthesized with a sand mould. (1) The following chemical compositions (measured, wt.\%) are utilized in Experiment I: C 0.47, Si 0.26, Mn 0.54, S 0.016, P 0.020, T.O 0.0056 and Fe balanced. The steel was melted at $1,600^{\circ} \mathrm{C}$ by an induction furnace and poured at $1,550^{\circ} \mathrm{C}$ in the atmosphere after the $\mathrm{Al}$ deoxidation (AD) process. (2) The following chemical compositions are utilized in Experiment II: C 0.47 , Si 0.44, Mn 0.49, S 0.005, P 0.005, T.O 0.001 and Fe balanced. It was refined and poured in vacuum conditions with both $\mathrm{Al}$-free and vacuum carbon deoxidation (VCD) techniques. (3) The following chemical compositions are utilized in Experiment III: C 0.44, Si 0.51, Mn 0.68, S 0.013, P 0.006, T.O 0.0015 and Fe balanced. The experimental methods are similar to the methods employed in Experiment II. 4) The following chemical compositions are utilized in Experiment IV: C 0.07, Si 1.34, Mn 2.32, Cr 9.62, W 1.52, V 0.25, S 0.005, P 0.007, T.O 0.0020 and Fe balanced. The experimental methods are similar to the methods employed in Experiment II. (5) The following chemical compositions are utilized in Experiment V: C 0.45, Si 0.54, Mn 0.64, S 0.008, P 0.009, T.O 0.0007 and Fe balanced. The VCD technique has been applied in the melting and refining stages of the molten steel while no $\mathrm{Al}$ was added. After the refining process, the level of oxygen concentration at T.O $=0.0007$ has been yielded in the melt and argon has been subsequently pumped into the furnace chamber to increase the maximum pressure to one atmosphere for pouring; it was poured at $1,550^{\circ} \mathrm{C}$. For these five ingots, the sand mould was used to produce a $500 \mathrm{~kg}$ round ingot. The as-cast ingot was cut in half along the longitudinal axis. After the ingot was grinded, polished and etched by a $20 \% \mathrm{HNO}_{3}-5 \% \mathrm{H}_{2} \mathrm{SO}_{4}-\mathrm{H}_{2} \mathrm{O}$ solution, a $20 \% \mathrm{HNO}_{3}-\mathrm{H}_{2} \mathrm{O}$ solution and a $5 \% \mathrm{HNO}_{3}-\mathrm{H}_{2} \mathrm{O}$ solution, respectively, $\mathrm{CS}$ was observed. The inclusions in samples cut from the CS zone were observed and identified by scanning electron microscopy (SEM) and energy dispersive spectroscopy (EDS).

Three 100-ton 30Cr2Ni4MoV ingots (Experiments VI, VII and VIII) have been experimentally synthesized with a cast iron mould. (1) The following chemical compositions (measured, wt.\%) are utilized in Experiment VI: C 0.22, Si 0.01, Mn 0.13, Cr 1.7, Ni 3.4, Mo 0.30, V 0.086, S 0.005, P 0.006, T.O 0.001 and Fe balanced. (2) The following chemical compositions are utilized in Experiment VII: C 0.22, Si 0.07, Mn 0.06, Cr 1.6, Ni 3.4, Mo 0.28, V 0.08, S 0.002, P 0.005, T.O 0.0015 and Fe balanced. (3) The following chemical compositions are utilized in Experiment VII: C 0.22, Si 0.01, Mn 0.06, Cr 1.67, Ni 3.6, Mo 0.27, V 0.08, S 0.003 , P 0.005, T.O 0.0012 and Fe balanced. The three ingots VI, VII and VIII have been produced by the following processes: electric arc furnace-ladle furnace-vacuum degassing and mould stream degassing. The vacuum pouring temperature is 
controlled to $1,575^{\circ} \mathrm{C}$. Note that, in both VI and VIII, the VCD technique was adopted; however, the $\mathrm{AD}$ technique was adopted for VII, and $0.014 \mathrm{wt} . \% \mathrm{Al}$ was fed in the ladle furnace to reduce the oxygen concentration. Subsequently, the three as-cast ingots were cut in half along the longitudinal axis. After the ingot sections were grinded, polished and etched by a $20 \% \mathrm{HNO}_{3}-5 \% \mathrm{H}_{2} \mathrm{SO}_{4}-\mathrm{H}_{2} \mathrm{O}$ solution, a $20 \% \mathrm{HNO}_{3}-\mathrm{H}_{2} \mathrm{O}$ solution and a $5 \% \mathrm{HNO}_{3}-\mathrm{H}_{2} \mathrm{O}$ solution, respectively, the CS was examined (see Supplementary Movie 3). The experiments demonstrated that the maximum measured solidification times are $27 \mathrm{~h}$ for VI and $32 \mathrm{~h}$ for VII and VIII.

3D X-ray characterisations. The volume fraction of OIs in the CS in the steel ingot of Experiment I has been measured using the 3D high-resolution transmission X-ray tomography (HRTXRT) technique with the lab-based Xradia Versa XRM-500 system. X-ray tomography imaging was performed for the cylindrical $(\Phi 3 \times 25 \mathrm{~mm})$ or rectangular $(4 \times 4 \times 35 \mathrm{~mm})$ specimens that were cut from the CS region. The working accelerating voltage was $140 \mathrm{kV}$. A total of 1,600 images, which were each exposed for $4 \mathrm{~s}$, were recorded as the sample was rotated by $360^{\circ}$ and computationally reconstructed via a filtered back projection algorithm to produce a 3D image with a voxel size of $\sim 3.5 \mu \mathrm{m}$. The equivalent volume diameter method was employed to obtain the dimensions of OIs.

First-principles calculations. The modelling simulations have been performed using the Vienna $\mathrm{Ab}$ initio Simulation Package (VASP) ${ }^{30}$ within the framework of the density functional theory, based on the plane-wave method. We adopted the generalized-gradient-approximation within the Perdew-Burke-Ernzerhof (PBE) parameterization scheme for the exchange-correlation function. Brillouin zone integrations were performed for the $k$-mesh $5 \times 5 \times 1$ according to the Monkhorst and Pack technique. The energy cutoff for the plane-wave expansion of the eigenfunctions was set to $400 \mathrm{eV}$. The optimization of the structural parameters was achieved by the minimization of the forces and stress tensors. The simulation primarily focuses on the interactions among the $\mathrm{S}$ atom, the $\mathrm{Mn}+n \mathrm{~S}$ atom complex and the surface of the solid alumina, which frequently appears in the steel melt. To establish the modelling system, we made two assumptions: (1) that the element $\mathrm{S}$ is considered to be the $\mathrm{S}$ atom or the $\mathrm{Mn}+n \mathrm{~S}$ atom complex in the melt and (2) the interfacial interactions among the alumina, $\mathrm{S}$ atom and $\mathrm{Mn}+n \mathrm{~S}$ atom complex with the iron melt is disregarded. We have selected $\alpha$-alumina $\left(\alpha-\mathrm{Al}_{2} \mathrm{O}_{3}\right)$ as the modelling structure. The optimized lattice constants, the enthalpy of formation $\left[\Delta H=-153.99 \mathrm{~kJ}\right.$ (mole of atoms) $\left.{ }^{-1}\right]$, the bulk band gap $\left(E_{\mathrm{g}}=5.9 \mathrm{eV}\right.$ at the $\Gamma$-point) of the bulk $\alpha-\mathrm{Al}_{2} \mathrm{O}_{3}$ corresponds with the previously reported results. Along the [0001] direction, the stacking sequence can be viewed as $\mathrm{O}-\mathrm{Al}-$ $\mathrm{Al}-\mathrm{O}-\mathrm{Al}-\mathrm{Al}-\mathrm{O}$. The distance between any two adjacent O layers is $\sim 2.2 \AA$ in the bulk equilibrium phase. Therefore, three (0001) surface terminations are currently available, namely, the Al-, AlO- and O-terminated surfaces. Consistent with the reported results, the clean AlO-terminated (0001) surface has been energetically most favourable result with the lowest surface energy of $1.68 \mathrm{~J} \mathrm{~m}^{-2}$. Note that our calculations have been based on the non-dipole AlO-terminated surface, which denotes a single outermost Al-layer and a sub-outermost O-layer. The optimized surface structure indicates that the space distance between the topmost layer and the second layer is significantly reduced $(\Delta l \approx 0.738 \AA$ being $\sim 78 \%$ of the unrelaxed distance). These results show that the topmost $\mathrm{Al}$ atom is almost in the same layer as the second oxygen layer. This situation is attributed to the finding that the coordination number of the topmost $\mathrm{Al}$ atom is much less than the crystal. To simulate the adsorption on the surface of $\alpha-\mathrm{Al}_{2} \mathrm{O}_{3}$, we constructed a slab with an 18-layer-thickness, a $15 \AA$ vacuum depth along the [0001] direction, and a surface unit cell with a $2 \times 2$ dimension. For all surface calculations, the bottom nine layers have been kept frozen; the other nine layers have been allowed to relax.

Macro/meso-scale simulations. The theoretical model of multiphase flow, which considers the effect of the melt on the particles and the particles on the melt flow distribution, is incorporated into the macrosegregation model within the classical theoretical framework. The discrete phase model $^{31}$ is employed to calculate the flotation of particles, in which the trajectories of the particles that move in the flow field have been computed using a Lagrangian approach. The particle-fluid interactions are considered by encompassing the effect of the melts on the particle trajectories and the effect of the particles on the melts flow distribution. Details of the Lagrangian modelling approach for the treatment of particle motion have been reported elsewhere ${ }^{31}$. The formulations of the macrosegregation model are provided in Supplementary Note 7. In addition, all particles are assumed to exhibit a spherical shape. Before solidification, the liquid is stationary and particles are randomly injected into the melt in space. The two types of simulated solidification process are sketched in Supplementary Fig. 29. The density of the molten carbon steel Fe- 0.36 wt.\% C $\left(\rho_{1}\right)$ and the $\mathrm{Al}_{2} \mathrm{O}_{3}$ particles $\left(\rho_{\mathrm{p}}\right)$ are 6.99 and $3.64 \mathrm{~g} \mathrm{~cm}^{-3}$, respectively. The dynamic viscosity of the steel melt $\mu$ is equivalent to $0.0042 \mathrm{~Pa} \cdot \mathrm{s}$.

To assess the solute convection in advance of the dendritic solidification front, the quantitative two-dimensional Karma phase-field model for the binary alloy solidification ${ }^{32}$ in the coupling of fluid flow dynamics has been adopted to investigate the evolution of the solid-liquid interface in the condition of melt flow. In this model of the crystallization, the evolution of the phase state has been described as a function of the order parameter $\psi$, the composition $C$ and the temperature $T$. The ordering parameter $\psi$ has a constant value in the solid and liquid phases and varies smoothly across the thin diffuse solid-liquid interface. The transport of solute in liquid has been induced not only by diffusion but also by convection. Assuming that the fluid is incompressible, the Navier-Stokes equations have been considered to describe the fluid motion. The gravity-driven natural convection induced by solute and thermal expansion has been considered via a source term in the viscous equation using a Boussinesq approximation ${ }^{8}$. To depict the evolution of thermosolutal convection in the regions between columnar dendrites, a conventional upward directional solidification of $\mathrm{Fe}-0.36 \mathrm{wt} . \% \mathrm{C}$ alloy has been employed with several different processing parameters. The calculations have been performed on a $2,117 \times 6,880 \mu \mathrm{m}^{2}$ rectangular grid via an adaptive mesh and parallel computing procedure. A vertical temperature gradient of $37^{\circ} \mathrm{Ccm}^{-1}$ has been established, in which the top is hotter than the bottom, and the isotherm rate varies from 13.5 to $1,081.1 \mu \mathrm{m} \mathrm{s}^{-1}$. Details of the model and numerical implementations are provided in Supplementary Note 6. The computational parameters employed in the numerical simulations are listed in Supplementary Table 4.

\section{References}

1. Mehrabian, R., Keane, M. A. \& Flemings, M. C. Experiments on macrosegregation and freckle formation. Metall. Trans. 1, 3238-3241 (1970).

2. Hunt, J. D. Solidification and Casting of Metals (The Metals Society, 1979).

3. Kerr, R. C., Woods, A. W., Worster, M. G. \& Huppert, H. E. Disequilibrium and macrosegregation during solidification of a binary melt. Nature 340, 357-362 (1989).

4. Flemings, M. C. Solidification Processing (McGraw-Hill, 1974).

5. Beckermann, C. Modeling of macrosegregation: Applications and future needs. Int. Mater. Rev. 47, 243-261 (2002).

6. Flemings, M. C. Our understanding of macrosegregation: past and present. ISIJ Int. 40, 833-841 (2000).

7. Vannocio Biringuccio: Pirotechnia, (1540) transl. by Smith, C. S. \& Gnudi, M. T., AIME, New York, 254 (1942).

8. Worster, M. G. Convection in mushy layers. Annu. Rev. Fluid Mech. 29, 91-122 (1997).

9. Pickering, E. J. Macrosegregation in steel ingots: the applicability of modelling and characterisation techniques. ISIJ Int. 53, 935-949 (2013).

10. Yuan, L. \& Lee, P. D. A new mechanism for freckle initiation based on microstructural level simulation. Acta Mater. 60, 4917-4926 (2012).

11. Shevchenko, N., Boden, S., Gerbeth, G. \& Eckert, S. Chimney formation in solidifying Ga-25wt pct In alloys under the influence of thermosolutal melt convection. Metall. Mater. Trans. A 44, 3797-3808 (2013).

12. Connolly, J. A. D. \& Podladchikov, Y. Y. Decompaction weakening and channeling instability in ductile porous media: Implications for asthenospheric melt segregation. J. Geophys. Res. 112, B10205 (2007).

13. Andrault, D. et al. Solid-liquid iron partitioning in Earth's deep mantle. Nature 487, 354-357 (2012).

14. Kelemen, P. B., Shimizu, N. \& Salters, V. J. M. Extraction of mid-ocean-ridge basalt from the upwelling mantle by focused flow of melt in dunite channels. Nature 375, 747-753 (1995).

15. Kurz, W. \& Fisher, D. J. Fundamentals of Solidification (Trans Tech Publications, 1998).

16. Michelic, S. C., Thuswaldner, J. M. \& Bernhard, C. Polydimensional modelling of dendritic growth and microsegregation in multicomponent alloys. Acta Mater. 58, 2738-2751 (2010).

17. Combeau, H., Založnik, M., Hans, S. \& Richy, E. Prediction of macrosegregation in steel ingots: Influence of the motion and the morphology of equiaxed grains. Metall. Mater. Trans. B 40, 289-304 (2008).

18. Brown, S. G. R., Spittle, J. A., Jarvis, D. J. \& Walden-Bevan, R. Numerical determination of liquid flow permeabilities for equiaxed dendritic structures. Acta Mater. 50, 1559-1569 (2002).

19. Li, J., Wu, M., Hao, J. \& Ludwig, A. Simulation of channel segregation using a two-phase columnar solidification model - Part I: Model description and verification. Comput. Mater. Sci. 55, 407-418 (2012).

20. Li, J., Wu, M., Hao, J., Kharicha, A. \& Ludwig, A. Simulation of channel segregation using a two-phase columnar solidification model - Part II: Mechanism and parameter study. Comput. Mater. Sci. 55, 419-429 (2012).

21. Gandin, Ch.-A., Mosbah, S., Volkmann, T. h. \& Herlach, D. M. Experimental and numerical modeling of equiaxed solidification in metallic alloys. Acta Mater. 56, 3023-3035 (2008).

22. Kajikawa, K. et al. Development of 650-ton-class ingot for turbine rotor shaft forging application. In 1st International Conference on Ingot Casting, Rolling and Forging (Aachen, 2012).

23. Steel Statistical Yearbook 2013 (World Steel Association, 2013).

24. Kimura, S., Nabeshima, Y., Nakajima, K. \& Mizoguchi, S. Behavior of nonmetallic inclusions in front of the solid-liquid interface in low-carbon steels. Metall. Mater. Trans. B 31, 1013-1021 (2000).

25. Beckerman, C., Gu, J. P. \& Boettinger, W. J. Development of a freckle predictor via Rayleigh number method for single-crystal nickel-base superalloy castings. Metall. Mater. Trans. A 31, 2545-2557 (2000). 
26. Yang, W. H. et al. A freckle criterion for the solidification of superalloys with a tilted solidification front. JOM 9, 56-61 (2004).

27. Hebditch, D. J. \& Hunt, J. D. Observations of ingot macrosegregation on model systems. Metall. Trans 5, 1557-1564 (1974).

28. Sawada, T., Oikawa, K. \& Anzai, K. Three-dimensional numerical simulation of channel segregation in directionally solidified Sn-20 mass\% Bi ingot. Tetsu-toHagane 99, 135-140 (2013).

29. Cao, Y. F., Chen, Y., Fu, P. X., Liu, H. W. \& Li, D. Z. The experimental characterisation of the channel segregation formation in $27 \mathrm{SiMn}$ steels. Unpublished work.

30. Kresse, G. \& Furthmuller, J. Efficient iterative schemes for ab initio total-energy calculations using a plane-wave basis set. Phys. Rev. B 54, 11169-11186 (1996).

31. Gouesbet, G. \& Berlemont, A. Eulerian and Lagrangian approaches for predicting the behaviour of discrete particles in turbulent flows. Prog. Energy Combust. Sci 25, 133-159 (1999).

32. Karma, A. Phase-field formulation for quantitative modeling of alloy solidification. Phys. Rev. Lett. 87, 115701 (2001).

\section{Acknowledgements}

The authors acknowledge the valuable discussions with Professor M. C. Flemings from the Massachusetts Institute of Technology in the USA, Professor J. Campbell from the University of Birmingham in the U.K. and Dr V.M. Shcheglov from the Physico-Technological Institute of Metals and Alloys at the National Academy of Sciences of Ukraine; the experimental assistance by Xiuying Gai and Jingping Cui from the Technique Support Division; the discussions related to the geological fields with Professor Zhida Bai from the China University of Geosciences; and the contributions by Lijun Xia, Xiuhong Kang, Mingyue Sun, Xiaoqiang Hu, Dongrong Liu, Baoguang Sang and Pengyue Wei from the Institute of Metal Research, as well as the financial support from the international cooperation project (No. 2010DFR70640) from the Ministry of Science and Technology, China, the strategic priority research program of Chinese
Academy of Sciences (No. XDA03010304) and the Chinese national S\&T major project (No. 2011ZX060004-016-002).

\section{Author contributions}

D.L. proposed the effect of OIs on channel segregation. P.F., H.L. and Y.Lu. performed the ingot casting, compositions analysis and observation of channel segregation. X.M. performed the inclusion measurements and analyses in the channel segregate regions. X.-Q.C. performed the density functional theory calculations. Y.Ch. performed the mesoscale simulations and Y.Ca. performed the process scale simulations of OI-induced CS formation. Y.Li. proposed the original problem and supervised the investigation. D.L. and X.-Q.C. wrote the paper with assistance from all authors. All authors contributed to the discussions in the manuscript.

\section{Additional information}

Supplementary Information accompanies this paper at http://www.nature.com/ naturecommunications

Competing financial interests: The authors declare no competing financial interest.

Reprints and permission information is available online at http://npg.nature.com/ reprintsandpermissions/

How to cite this article: $\mathrm{Li}, \mathrm{D}$. et al. Inclusion flotation-driven channel segregation in solidifying steels. Nat. Commun. 5:5572 doi: 10.1038/ncomms6572 (2014).

\section{(c) (1)}

This work is licensed under a Creative Commons Attribution 4.0 International License. The images or other third party material in this article are included in the article's Creative Commons license, unless indicated otherwise in the credit line; if the material is not included under the Creative Commons license, users will need to obtain permission from the license holder to reproduce the material. To view a copy of this license, visit http://creativecommons.org/licenses/by/4.0/ 


\section{Corrigendum: Inclusion flotation-driven channel segregation in solidifying steels}

Dianzhong Li, Xing-Qiu Chen, Paixian Fu, Xiaoping Ma, Hongwei Liu, Yun Chen, Yanfei Cao, Yikun Luan \& Yiyi Li

Nature Communications 5:5572 doi: 10.1038/ncomms6572 (2014); Published 25 Nov 2014; Updated 9 Feb 2015

In this Article, Supplementary Movies 1 and 2 were incorrectly associated with experiments VII and VIII, respectively. Instead, Supplementary Movie 1 corresponds to experiment VI and Supplementary Movie 2 corresponds to experiment VII. 